\title{
Capacidade Reprodutiva de RATAS ALEITADAS POR MÄES QUE RECEBERAM LEVONORGESTREL DURANTE A LACTAÇ̄OO
}

\author{
Martha de Oliveira Guerra*, Evelise Rocha de Souza, Vera Maria Peters \\ Trabalho realizado no Centro de Biologia da Reprodução - Universidade Federal de Juiz de Fora, MG
}

RESUMO - 0 levonorgestrel é um dos contraceptivos usados por mulheres durante a lactação. Estudos prévios mostraram que a administração de levonorgestrel a ratas lactando causou nas crias retardo de puberdade em machos e alterações no peso de oviduto e útero.

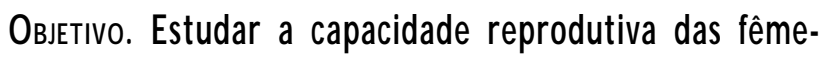
as $F_{1}$, de mães tratadas com levonorgestrel.

Métodos. Ratas Wistar foram tratadas com levonorgestrel $(0.030 \mathrm{mg} / 1 \mathrm{ml}$ de água destilada) do 70 ao 130 dia após 0 nascimento (dia $1=$ nascimento). Aos 90 dias, as fêmeas $F_{1}$ foram acasaladas com machos férteis e a inseminação comprovada pela presença de espermatozóides no esfregaço vaginal (primeiro dia de prenhez). As fêmeas inseminadas foram distribuídas em três lotes de 20 animais ( $10 F_{1}$ Controles e $10 F_{1}$ Tratadas). $0 s$ animais foram sacrificados no 20, 40 e 50 dias após a inseminação, por excesso de inalação com éter, e os ovários, ovidutos e cornos uterinos foram removidos. 0 s ovários foram pesados e os corpos lúteos contados. Ovidutos e cornos uterinos foram lavados com solução fisiológica e os préembriões obtidos foram contados e examinados em cada um dos segmentos.

Resultados, 0 peso de ovários, número de corpos lúteos, número e fase de desenvolvimento de pré-embriōes foram semelhantes nos dois grupos.

Conclusão. No modelo experimental usado, 0 aleitamento de crias de ratas por mães tratadas com levonorgestrel não interfere com a capacidade reprodutiva de fêmeas $F_{1}$.

Unitermos: Levonorgestrel. Lactação. Ratas. Reprodução.

\section{INTRODUÇÃO}

Sabe-se que a amamentação é um método contraceptivo natural. No entanto, não há total proteção contra a gravidez ao longo de todo o período de lactação ${ }^{1-4}$. A infertilidade é temporária, sendo da ordem de 1,8\% o risco de gravidez em mulheres amenorréicas que estão amamentando. Devido a este fato, recomenda-se o início do uso de contraceptivos ainda no período de lactação $0^{5,6,7}$.

Contraceptivos hormonais ou não hormonais são utilizados durante a lactação. No entanto, existem dúvidas

\footnotetext{
*Correspondência:

Rua São Mateus, 711. Ap. 103C - 36025-001

Juiz de Fora. MG - Tel: (32) 229-3253

Fax: (32) $3229-3255$
}

quanto ao efeito que os contraceptivos possam causar na produção de leite no crescimento do recém-nascido, e se o hormônio eventualmente ingerido com o leite possa afetar o comportamento sexual e reprodutivo da cria quando atingir a vida adulta ${ }^{5,1,8,2,6,9,7}$.

Entre os contraceptivos hormonais, o levonorgestrel é um contraceptivo progestagênico considerado adequado para o uso humano durante o período de lactação, $5,1,10,11,12$. 0 levonorgestrel é excretado no leite em pequenas quantidades ${ }^{13-15}$, em concentrações ao redor de 23 a 31 l pg/ $\mathrm{ml}$. A dose ingerida pelo recém-nascido é estimada em 15 a $18 \mathrm{ng} / \mathrm{Kg} / \mathrm{dia}$ durante o primeiro mês de tratamento materno (período da concentração sanguínea mais elevada)' ou em I,3\% a $9 \%$ da dose diária de levonorgestrel, ajustada ao peso ${ }^{16,14}$. Com tal concentração no leite, parece pouco provável que o levonorgestrel represente algum risco para a saúde da criança', além disso, acredita-se que o recém-nascido não o absorva eficientemente ${ }^{17}$.

O mecanismo de ação contraceptiva do levonorgestrel envolve inibição da ovulação, alteração da fase lútea, modificação do muco cervical, que se torna menos penetrável ao espermatozóide, indução de desenvolvimento inadequado do endométrio secretor ${ }^{18}$, interferência com a penetração do espermatozóide no ovócito ou com eventos relacionados à pré-implantação ${ }^{19}$ e alteração da maturação do ovócito ${ }^{20,21}$. 
Em ratas, o levonorgestrel inibe a produção de progesterona, induzida nas células lúteas pelo $\mathrm{LH}{ }^{(22)}$ e reduz o número de receptores para estrogênio e progesterona no ovário e endométrio ${ }^{23}$.

Em mulheres, a implantação na pele de cápsulas contendo $36 \mathrm{mg}$ de levonorgestrel, após um primeiro momento de concentrações sanguíneas altas, atinge a média de $400 \mathrm{pg} / \mathrm{ml}$, que vai decrescendo gradualmente ao passar do tempo ${ }^{18}$.

Em avaliações anteriores, Guerra et al., 1999, 200024,25, usando doses de $15 \mathrm{mg}$ ou $30 \mathrm{mg}$ (3 vezes ao dia) de levonorgestrel, observaram alterações no crescimento e nos pesos de alguns órgãos de crias na puberdade e na vida adulta de ratos. Em machos, a puberdade foi atrasada em um dia. Porém, nesses trabalhos não foram avaliados os aspectos relativos à capacidade reprodutiva dessas crias quando atingem a idade adulta.

Neste trabalho, administraram-se $30 \mathrm{mg}$ de Levonorgestrel (três vezes ao dia) a ratas lactando e acompanhou-se o desempenho reprodutivo das crias do sexo feminino $\mathrm{Fl}$ através da avaliação do desenvolvimento embrionário inicial (fase de 2 células, mórula e blastocisto).

\section{Métodos}

Para este estudo foram utilizadas ratas Wistar gestantes (20 dia de gestação), obtidas do Biotério do Centro de Biologia da Reprodução - Universidade Federal de Juiz de Fora.

As ratas foram colocadas em gaiolas individuais, onde permaneceram desde o parto até o final da lactação. No dia do parto as ratas foram distribuídas aleatoriamente em dois grupos: controle e tratado.

As ratas do grupo tratado receberam levonorgestrel (30 mg em I ml de água destilada / via gástrica), às 8h30;
IIh30; I 5 h30 (horários em que se verifica maior número de ninhadas amamentando). As ratas do grupo controle receberam I ml de água destilada, seguindo o mesmo esquema de tratamento usado no grupo tratado.

O tratamento iniciou-se no $7^{\circ}$ dia (seis dias antes da primeira ovulação espontânea do primeiro ciclo pós-parto $^{26}$ ) e terminou no $13^{\circ}$ dia de vida pós-natal, quando as crias passam a ingerir alimentos sólidos ${ }^{27}$.

Foi considerado o primeiro dia de vida pós-natal, o intervalo de tempo de até 24 horas após o parto. As ninhadas nascidas de mães controles $(F \mid C)$ e de mães tratadas $(F \mid t)$ foram acompanhadas diariamente de forma a se verificar a ocorrência de mortes, canibalismos ou abandono das crias. O desmame foi feito no $24^{\circ}$ dia de vida, quando machos e fêmeas foram separados em gaiolas individuais.

Aos 90 dias de vida, as fêmeas de FI foram acasaladas (3 fêmeas : I macho) e a inseminação foi comprovada pela presença de espermatozóides no esfregaço vaginal, sendo este dia, considerado o primeiro dia de prenhez. As fêmeas inseminadas foram distribuídas em lotes de 20 animais $(10 \mathrm{Flc}$ e $10 \mathrm{Flt}$ ) que foram sacrificados (excesso de inalação de éter) nos dias dois, quatro ou cinco da prenhez, entre 9h e 9h30.

Cada animal foi pesado, submetido a laparotomia e, em seguida, cornos uterinos, ovidutos e ovários foram removidos e colocados imediatamente em solução fisiológica. Os ovários foram pesados juntos e, nos animais com cinco dias de prenhez, os corpos lúteos de gestação foram contados de forma a se estabelecer o índice de perdas nas fases prévias a blatocisto (IP $(\%)=[1$ - Total de pré-embriões/ Total de corpos lúteos] X 100.

Os ovidutos e os cornos uterinos foram perfundidos com solução fisiológica, e o líquido de lavagem foi recolhido em cápsulas embrionárias, onde os pré-embriões coletados foram examinados, contados e classificados, segundo seu desenvolvimento e sua posição no trato reprodutor.

Os pesos corporais maternos foram analisados pelo teste de "t" de Student (pareado) e os dados contínuos, pelo teste do qui-quadrado. Nível de significância dos testes alfa $=0.05$.

$\mathrm{O}$ experimento foi submetido e aprovado pelo Comitê de Ética do Centro de Biología da Reprodução.

\section{Resultados}

Não foram observadas mortes maternas de crias, canibalismo ou abandono de crias durante o período de tratamento materno.

$O$ peso corporal das fêmeas $\mathrm{FI}$ nos diferentes dias de prenhez encontra-se na Tabela I.

Observa-se que os pesos corporais de Flc e Flt foram semelhantes.

A média de peso dos ovários de fêmeas Flc e Flt, nos respectivos dias de prenhez, encontra-se expressa na Tabela 2.

Nota-se que no $5^{\circ}$ dia de prenhez os ovários de Flt foram mais pesados que os de FIc $(p<0.05)$, sendo semelhante nos demais grupos experimentais.

Nos animais controles e nos tratados, mortos aos dois dias da prenhez, foram encontrados pré-embriões em fase de duas células, todos localizados no oviduto. No quarto dia de prenhez foram encontradas mórulas também no oviduto e no quinto dia, os préembriões já estavam todos nos cornos uterinos e na fase de blastocisto.

A média de blastocistos e de corpos lúteos no grupo sacrificado no quinto dia de prenhez encontra-se resumida na Tabela 3

Não ocorreram diferenças significativas entre os dois grupos experimentais. 
Tabela 1 - Peso corporal (g) de ratas tratadas com levonorgestrel ( $30 \mathrm{mg} / 3$ vezes ao dia) ou controle ( $1 \mathrm{ml}$ de água destilada/3 vezes ao dia); Sacríicio no $2^{\circ}, 4^{\circ}$ e $5^{\circ}$ dias de prenhez DIA DE PRENHEZ

\begin{tabular}{lcc} 
& Controle & Tratado \\
2 & $176.4 \pm 14.13(10)$ & $169.4 \pm 10.67(10)$ \\
4 & $175.6 \pm 16.68(10)$ & $182.2 \pm 13.70(10)$ \\
5 & $177.6 \pm 13.21(10)$ & $182.0 \pm 11.63(10)$ \\
\hline
\end{tabular}

Resultados expressos em média \pm desvio padrão.

Tabela 2 - Média de peso de ovários (mg) em ratas tratadas com levonorgestrel ( $30 \mathrm{mg} / 3$ vezes ao dia) ou controle ( $1 \mathrm{ml}$ de água destilada/ 3 vezes ao dia); Sacríicio no 20, 40 e 50 dias de prenhez

GRUPOS

2Días

4 Dias

5 Dias

Resultados expressos em média \pm desvio padrão. ${ }^{*} p>0.05$ em relação ao controle.
Tabela 3 - Número médio de blastocistos e de corpos lúteos em ratas, tratadas com levonorgestrel ( $30 \mathrm{mg} / 3$ vezes ao dia) ou controle ( $1 \mathrm{ml}$ de água destilada/3 vezes ao dia); Sacrifício no 50 dias de prenhez

\begin{tabular}{lll}
\hline & Controle & Tratado \\
Blastocistos & $8 \pm 2(10)$ & $8 \pm I(10)$ \\
Corpos lúteos & $11 \pm 2(10)$ & $10 \pm 1(10)$ \\
\hline
\end{tabular}

Resultado expresso em média \pm desvio padrão. Não ocorreu diferença significativa.

O índice de perdas nas fases antecedentes a blastocisto, calculado em animais sacrificados no quinto dia de prenhez, foi de 25\% (1 - 80/106) X100 para controle e de 19\% (I - 85/I04)X 100 para os tratados, não havendo diferença significativa entre os grupos.

\section{Discussão}

Drogas que causam toxicidade mater- na, quando administradas durante 0 período de, lactação podem alterar o comportamento materno e impedir que as crias sejam cuidadas adequadamente, afetando assim o seu desenvolvimento $e$, inclusive, reduzindo suas chances de sobrevivência.

Nos animais do grupo experimental tratado com levonorgestrel não se observaram mortes maternas, alteração da atividade locomotora, diarréia ou presença de pelos eriçados, indicando que, através de critérios clínicos, o levonorgestrel não teve efeito tóxico sobre a fêmea em lactaçãa $0^{28}$.

A capacidade reprodutiva de uma fêmea envolve aspectos variados da fisiologia reprodutiva: capacidade de produção de gametas adequados; produção hormonal equilibrada, alterações morfológicas e bioquímicas de oviduto e útero compatíveis com os processos de transporte de espermatozóides, zigoto, fases precoces e tardias do desenvolvimento do concepto.

Os corpos lúteos são responsáveis pelo sucesso da gestaçãa, visto serem a fonte principal da secreção de progesterona ${ }^{29}$, além disso, em princípio, a cada corpo lúteo corresponde uma ovulaçãa $0^{30}$. Sob tal ponto de vista, as fêmeas $F$, gestantes, provenientes dos grupos controle e tratado, possuíam mesmo número de corpos lúteos, portanto, a capacidade fisiológica do ovário poderia ser considerada como semelhante em $F$, de ambos grupos.

As alterações no desenvolvimento do pré-embrião (fase compreendida entre zigoto e aparecimento de linha primitiva) podem ser devido a lesão direta ou indireta de um agente tóxico. No primeiro caso, a lesão é diretamente sobre o concepto, e no segundo, pode decorrer de modificação do tempo de transporte até o útero prejudicando a sincronia necessária entre blastocisto e o desenvolvimento do endométrio, impedindo, desta forma, a implantação do blastocisto ${ }^{31}$.

O pré-embrião permanece por dois a cinco dias no oviduto, onde fica isolado do restante do trato reprodutor pela oclusão de duas junções: istmo-ampolar e úterotubária. Nessa região encontram-se nutrientes e fatores específicos necessários à sua sobrevivência e a seu desenvolvimento progressivo até a fase de blastocisto, quando a junção útero-tubária abre-se, permitindo a passagem do blastocisto para 0 útero ${ }^{32}$.

Uma das formas de se avaliar perdas de conceptos em fases precoces do desenvolvimento é correlacionar o número de corpos lúteos com o número de pré-embriões coletados no oviduto ou nos cornos uterino, visto que, idealmente, uma ovulação corresponderia a um ovócito fertilizável e a um embrião. O recolhimento de menor quantidade de pré-embriões indica mortes do concepto ou retenção no oviduto. $O$ índice de perdas, calculado entre os animais sacrificados no quinto dia de prenhez, mostra que elas foram semelhantes em ambos grupos experimentais, portanto pode-se supor que o ambiente hormonal e 
bioquímico do trato reprodutor das fêmeas foi semelhante.

A presença de pré-embriões em fase atrasada de seu desenvolvimento, ou em local onde deveria estar mais avançada, leva à suspeita de ação lesiva que retardou o seu processo de segmentação ou que acelerou seu trânsito pelo oviduto. Neste trabalho verificou-se que, conforme o esperado, aos dois dias de prenhez, encontravam-se conceptos em fase de duas células no oviduto; aos quatro dias, mórulas no oviduto enquanto que os blastocistos foram encontrados em cornos uterinos, aos cinco dias de

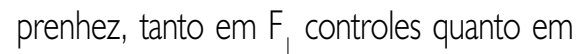
tratadas, o que sugere que o desenvolvimento ocorreu de modo semelhante tanto nos animais provenientes de mães controles quanto no de tratadas.

Os resultados encontrados levam à conclusão de que, no modelo experimental usado neste experimento, o levonorgestrel administrado a ratas lactando não afetou a capacidade reprodutiva de fêmeas $F$, no período gestacional estudado.

\section{Summary}

\section{Reproductive performance OF fema- LE WISTAR RAT, DESCENDENT OF MOTHERS TREATED WITH LEVONORGESTREL DURING THE LACTATION}

Levonorgestrel is one of the contraceptives used by women during lactation. Previous studies have shown that the administration of levonorgestrel to lactating female rats has affected the offspring, causing puberty delay in males and alterations on uterus and oviduct weight.

PURPOSE. Tostudy the reproductive capacity of $\mathrm{F} /$ females from rats treated with levonorgestrel.

METHODS. Female Wistar rats were treated with levonorgestrel $(0.030 \mathrm{mg} / \mathrm{l} \mathrm{ml}$ of distilled water) from day 7 to day 13 after birth (day I = birth). On day $90 \mathrm{FI}$ females were mated with fertile males and inse- mination was confirmed by the presence of spermatozoa in the vaginalsmear (first day of pregnancy). Inseminatedfemales were distributed in three groups of 20 animals each ( 10 $\mathrm{Fl}$ control and $10 \mathrm{Fl}$ treated). The animals were killed on days 2, 4 and 5 after insemination by ether overdose inhalation and the ovaries, oviducts and uterine cornua were removed. Theovarieswere weighedand the corpora lutea counted. Oviducts and corpora lutea were washed with saline solution and the pre-embryos were counted and examined in all segments.

REsULTS. The ovaries weight, the number of corpora lutea, the number and development phase of the pre-embryos were similar in both groups.

CONCLUSION. In the experimental modelused, FI females whose mothers were treated with levonorgestrel during lactation, did not show any alteration in their reproductive capacity. [Rev Assoc Med Bras 2002; 48(2): 135-9]

KEY WORDS: Levonorgestrel. Lactation. Rats. Reproduction.

\section{RefERÊNCIAS}

I. Díaz S, Herreros C, Juez G, Casado ME. Fertility regulation in nursing women: VIIinfluence of norplant ${ }^{\circledR}$ levonorgestrel implants upon lactation and infant growth Contraception 1985; 32:53-7

2. Peralta O, Díaz S, Casado ME, Croxatto HB. Influencia de un anticonceptivo oral combinado sobre la lactancia y el crecimiento del niño. Rev Chil Obstet Ginecol 1983; 48:372-80.

3. Perez A, Vela P, Masnick GS, Potter RG. First ovulation after childbirth: The effect of breast-feeding. Am J Obstet Gynecol 1972; 1। 4:1041-7.

4. Rivera R, Kennedy MAK, Ortiz RNE, Barrera BAM, Bhiwandiwala MDPP. Breast-feeding and return to ovulation in Durango, Mexico. Fertil Steril I 988; 49:780-7.

5. Campodonico I, Guerrero B, Landa L. Effect of a low-dose contraceptive (I50 $\mu \mathrm{g}$ levonorgestrel and $30 \mu \mathrm{g}$ ethinylestradiol) on lactation. Clin Ther 1978; 1:454-9.

6. Peralta O, Díaz S, Casado ME, Juez G, Herreros C, Salvatierra AM, et al. Anticoncepción con pellets de progesterona durante la lactancia. Rev Chil Obstet Ginecol 1984; 49:337-45.
7. Tankeyoon M, Dusitsin N, Chalapati S, Koetsawang S, Saibiang S, Sas M, et al. Effects of hormonal contraceptives on milk volume and infant growth. Contraception 1984; 30:505-22.

8. Holzhausen C, Murphy S, Birke LIA. Neonatal exposure to a progestin via milk alters subsequent LH cyclicity in the female rat. J. Endocrinol 1984; 1 00: 1 49-54, apud: Harlap S. Effects on progeny of exposure to hormonal contraceptives in uterus or through breast milk. In: Michal F. Safety requirements for contraceptive steroids. Cambridge: Cambridge University Press; 1989. p. 126-47.

9. Satayasthit N, Tankeyoon M, Chaudhury RR. The effect of medroxyprogesterone acetate, administered to the lactating rat, on the subsequent growth, maturation and reproductive function of the litter. J Reprod Fertil 1976; 46:4 I I 12, apud Harlap S. Effects on progeny exposure to hormonal contraceptive in uterus or through breast milk. In: Michal F. Safety requirements for contraceptive steroids, Cambridge: Cambridge University Press; 1989. p. I26-47.

10. Díaz S, Zepeda A, Maturana X, Reyes MV, Miranda $P$, Casado ME, et al. Fertility regulation women. IX. Contraceptive performance, duration of lactation, infant growth, and bleeding patterns during use of progesterone vaginal rings, progestin-only pills, norplant ${ }^{\circledR}$ implants, and cooper - T-380-a intrauterine devices. Contraception 1997; 56:223-32.

I I. Díaz S, Cardenas H, Brandeis A, Miranda P, Salvatierra AM, Croxatto HB, et al. Relative contributions of anovulation and luteal phase defect to reduce pregnancy rate of breast feeding women. Fertil Steril 1992; 14:498-503.

12. WHO Task force for epidemiological resear on reproductive Health. Progestagen-only contraceptives during lactation: I. Infant growth. Contraception 1994; 50:35-53.

13. Nilsson S, Nygren KE, Hohansson EDB. Dnorgestrel concentration in maternal plasma, milk and child plasma during administration of oral contraceptives to nursing men. Am J Obstet Gynecol 1977; 129: 178- 83.

14. Thomas MJ, Danutra V, Read GF, Hillier SG, Griffiths K. The detection and measurement of D- norgestrel in human milk using sephadex LH20 chromatography and radioimmunoassay. Steroids 1977; 32:349-51.

15. Toddywalla VS, Mehta S, Virkar KD, Saxena BN. Release of 19-nortestosterone type of contraceptive steroids through different drug delivery systems into serum and breast milk of lactating women. Contraception 1980; 21:217-22.

16. Bennet PN, editor. Drugs and human lactation. Amsterdan: Elsevier; 1988. p. 164-5.

17. Patel SB. At what "infant-age" can levonorgestrel contraceptives be recommended to nursing mothers? Adv Contracept 1994; 10:249-55.

18. Fraser IS, Tiitinen A, Affandi B, Brache V, Croxatto HB, Diaz S, et al. Norplant ${ }^{\circledR}$ consensus statement and background review. Contraception 1998; 57:1-9. 
19. Croxatto H B, Díaz S, Pavez M, Miranda P, Brandeis A. Plasma progesterone levels during long - term treatment with levonorgestrel silastic implants. Acta Endocrinol 1982; 101:307-I I.

20. Alvarez, F, Brache V, Tejada AS, Faúndes A. Abnormal endocrine profile among women with confirmed or presumed ovulation during long-term norplant ${ }^{\circledR}$ use. Contraception 1986; 33: I II-9.

21. Segal SJ, Alvarez FS, Brache V, Faundes A, Vilja $P$, Tuohimaa $P$, et al. Norplant ${ }^{\circledR}$ implants: the mechanism of contraceptive action. Fertil Steril 1991: 56:273-7.

22. Telleria CM, Carrizo DG, Deis RP. Levonorgestrel inhibits luteinizing hormonestimulated progesterone production in rat luteal cells. J Steroid Biochem Mol Biol 1994; 50:6I-6.

23. Sun $A$, Chen $X$, Kuang J. Effects of levonorgestrel subdermal implants on estradiol and progesterone receptors of endometrium and ovarian tissues in rats. Chung Hua Fu Chang Ko Tsa Chih 1996; $31: 530$.
24. Guerra MO, Oliveira LE, Lage LV, Souza ER, Peters VM. Levonorgestrel administration during rat lactation: offspring development. Ciênc Cult (São Paulo) 1999; 51:50-4.

25. Souza ER, Oliveira LEG, Guerra MO, Peters VM. Administração de levonorgestrel a ratas lactando: desenvolvimento físico das crias. Bol Centro Biol Reprod 2000; 19:4I-54.

26. Van der Schoot P, Uilenbroek JT, Slappendel E). Failure of two progesterone antagonist, mifepristone (RU- 38, 486) and onapristone, to affect luteal activity in lactating rats. J Reprod Fertil 1989; 87:593-601

27. Rothsschild A, editor. Manual para técnicos de biotério. São Paulo: Escola Paulista de Medicina/FINEP; 1990. p. 109

28. Manson JM, Kang, YJ. Test methods for assessing female reproductive and developmental toxicology. In: Hayes AW. Principles and methods of toxicology. New York : Raven Press; 1994. p.989- 1037.
29. Kato H, Morishige, WK, Rotchild I. A quantitative relationship between the experimentally determined number of conceptuses and corpus luteus activity in pregnant rat. Endocrinology 1979; 105:846-50.

30. Inman OR, Markivee CR. Gross effects on rabbit embryos and newborns of x-irradiation in the blastocyst stage. Anat Rec 1963; 174: I39-47.

31. Roblero LS, Fernandez O, Croxatto HB. The effect of RV 486 on transport, development and implantation of mouse embryos. Contraception 1987; 36: 549-55.

32. Moore GD, Croxatto HB. Effects of delayed treatment which estrogen on the J Reprod Fertil 1988; 83:795-802

Artigo recebido: 23/07/200 I Aceito para publicação: 20//2/200 I

\section{OPINÃO DO LTRR}

A nova Ramb abre espaço para o leitor na seção "Correspondências". Envie sua opinião ou sugestão sobre a revista ou artigos de seu interesse. Paticipe também enviando suas dúvidas ou sugestões sobre condutas práticas para a seção "À beira do leito". Sua colaboração é muito importante para aprimorarmos 0 nosso veículo de comunicação. Rua São Carlos do Pinhal, 324 Cep: 01333-903 São Paulo - SP - E-mail:ramb@amb.orgbr 